J. Lake Sci. (湖泊科学), 2015, 27(5): 783-790

DOI $10.18307 / 2015.0504$

(C) 2015 by Journal of Lake Sciences

\title{
湖泊生态水位计算新方法与应用”
}

\author{
涂 峰 ${ }^{1}$, 唐 琳 $^{2}$, 郭怀成 ${ }^{3}$, 高 伟 ${ }^{3 * *}$ \\ ( 1 : 江西省九江市环境保护监测站,九江 332000) \\ ( 2 : 北京大学城市与环境学院, 北京 100871 ) \\ (3: 北京大学环境科学与工程学院水沙科学教育部重点实验室,北京 100871)
}

摘 要: 水位是湖泊水文情势的主要特征指标, 对湖泊的水量、水质和生物的栖息地等有直接或间接的影响, 被认为是湖 泊生态系统健康的关键影响因素. 如何确定合理的湖泊水位以保证生态系统健康成为湖泊科学研究的重要科学问题. 根 据湖泊天然水位情势, 从天然水文变化中识别多项反映完整水位过程的指标,构建了湖泊生态水位的计算方法. 从湖泊 天然水位情势中提取出高、低水位的历时、发生时间和变化率等水位指数来表征其生态水位. 该方法弥补了传统湖泊生 态水位计算方法仅给出最小生态水位的不足,体现了湖泊生态系统健康对水位过程的要求. 基于提出的生态水位计算方 法和鄱阳湖都昌水位站 1952-2000 年共 49 年的日均监测数据,计算了鄱阳湖的生态水位目标值区间, 以期为鄱阳湖水 利工程生态调度提供决策依据.

关键词: 湖泊;生态水位;生态需水量;鄱阳湖;水位变化;水文变化指标法

\section{New method and application of estimating ecological water level of the Lake Poyang}

GAN Feng ${ }^{1}$, TANG Lin $^{2}$, GUO Huaicheng ${ }^{3} \&$ GAO Wei ${ }^{3}$

(1: Jiujiang Environmental Monitoring Station, Jiujiang 332000 , P. R. China)

(2: College of Urban and Environmental Sciences, Peking University, Beijing 100871, P. R. China)

(3: Key Laboratory of Water and Sediment Sciences, Ministry of Education, College of Environmental Sciences and Engineering, Peking University, Beijing 100871, P. R. China)

Abstract: Water level is a major feature and indicator of hydrological regimes of lakes, as affecting water volume, water quality and habitat of lakes. It is considered as a key factor affecting ecosystem health of lakes. How to estimate an ecological water level for lakes has long been an important scientific issue in lake science research. Based on multiple-year water level data of the Lake Poyang, water level indicators were identified from natural water level regimes to build up a new water level for the lake. Water level indices based on natural regimes are grouped as duration, timing, and rate of change for high and low water levels to represent lake ecological water level. The proposed method based on this study can improve lake ecological water level estimation by supplying a more detailed description of water level process which is not available from the traditional methods. Based on this new method and daily water level data of Duchang Station in the Lake Poyang from 1952 to 2000 , interval of ecological water level of the Lake Poyang was estimated to underpin the decision-making for ecological and water conservancy management of the Lake Poyang. Keywords: Lake; ecological water level; ecological water requirement; Lake Poyang; water level alteration; hydrology index method

我国是一个湖泊众多的国家, 拥有面积为 $1 \mathrm{~km}^{2}$ 以上的湖泊 2693 个,占国土面积的 $0.9 \%{ }^{[1]}$. 湖泊作为 自然生态系统的重要组成部分,具有调蓄洪水、涵养水源、保护生物多样性、提供水产品和消纳污染物等多 种生态功能 ${ }^{[2-3]}$. 然而, 由于水坝建设、围湖造田、生产生活取水等人类活动的干扰,我国湖泊的水文情势发

* 江西省科技厅软科学计划项目 (20122BBA10059) 资助. 2014-12-18 收稿; 2015-01-19 收修改稿. 涂峰 (1973 ) ,男,高级工程师;E-mail:jjhbgf@ 126. com.

** 通信作者;E-mail:jacob@ pku. edu.cn. 
生了显著变化, 特别是水位变化, 成为影响湖泊生态安全的重要因素之一 ${ }^{[3-6]}$. 研究湖泊的生态水文需求, 维 持湖泊生态系统健康是当今湖泊科学领域面临的重要科学问题 ${ }^{[7]}$. 在湖泊水文研究中, 水位和水量是反映 水文情势的重要水文指标. 因此, 湖泊的生态水文研究主要集中于计算湖泊的最低生态水位或最小生态需 水量, 认为湖泊最小水量或水位是满足湖泊生态系统健康的水文底线. 鉴于湖泊生态系统的动、植物功能和 结构与水位的密切联系 ${ }^{[8-11]}$, 应当将生态水位作为湖泊生态水文的重要研究对象. 由于湖泊水位与水量具有 一定的对应关系, 可以相互换算, 因此本研究并不严格区分生态水位与生态需水量.

目前关于湖泊生态水位 (或湖泊生态需水量) 的定义较多, 不同学者从水量平衡、资源利用、生态保护、 综合等多角度提出了不同界定. 其中, 生态系统的结构和功能完整性被作为湖泊生态水位的最主要保护目 标. 如李新虎等认为, 湖泊最低生态水位是维持生物多样性和生态系统完整性且不对生态环境及自身造成 严重破坏的最低运行水位 ${ }^{[12]}$; 崔保山等认为, 湖泊最小生态需水量是指为保证特定发展阶段的湖泊生态系 统结构稳定, 保护生物多样性以及确保湖泊水资源功能正常发挥所必须的、一定质量的最小水量 ${ }^{[7]}$; 徐志侠 等将湖泊生态系统不退化所需的最低水位作为湖区最低生态水位 ${ }^{[13]}$. 此外, 也有部分研究将某种生物 (鸟 类或者鱼类) ${ }^{[14]}$ 或物理环境 (水质) ${ }^{[15]}$ 作为湖泊生态水位的主要保护目标. 从生态水位的指标上看, 当前对 湖泊生态水位的界定主要是落脚于最小水位上 ${ }^{[7,12,14,16-21]}$, 即假设湖泊水位高于最小生态水位即可满足生态 系统健康要求. 然而, 众多研究表明, 湖泊生态过程不仅受最低水位影响, 还会受到最高水位、水位波动以及 持续时间的影响 ${ }^{[822-25]}$. 因此, 要实现湖泊的生态系统健康, 必须研究完整的水位情势, 而不是单一的水位特 征值. Coops 等在荷兰浅水湖泊的水位影响研究中, 提出恢复天然水位情势将有助于增强湖泊水质和生物多 样性的观点 ${ }^{[26]}$. 鉴于湖泊生态系统的复杂性和多样性, 笔者认为湖泊生态水位是指维持湖泊生态系统结构、 功能和过程完整性所需的水位情势, 包括水位的变化范围和过程. 据此, 湖泊生态水位的计算方法也必须能 够体现水位的多重属性. 然而, 目前主要的生态水位计算方法如曲线相关法、功能法和最低生态水位法 ${ }^{[7]}$ 的 结果均为单一值,难以提供全面的生态水位信息,亟需一种可反映完整水位过程的新方法.

本研究借鉴河流生态需水研究中的水文变化指标法 $(\mathrm{IHA})^{[27]}$, 提出一种用于计算湖泊生态水位的新方 法, 构建包括高低水位发生时间、持续时间和水位变化率等在内的生态水位指标体系, 并基于天然水位变化 特征给出了生态水位目标值范围. 以我国第一大淡水湖泊——鄱阳湖为例, 通过分析鄱阳湖的天然水位变 化情势, 获得其生态水位目标值范围, 以期为湖泊生态水文研究和鄱阳湖生态水文管理提供相关借鉴.

\section{1 材料与方法}

\section{1 研究区概况}

鄱阳湖 $\left(28^{\circ} 24^{\prime} \sim 29^{\circ} 46^{\prime} \mathrm{N}, 115^{\circ} 49^{\prime} \sim 116^{\circ} 46^{\prime} \mathrm{E}\right)$ 多年平均水域面积为 $3900 \mathrm{~km}^{2}$, 容积为 $290 \times 10^{8} \mathrm{~m}^{3}$, 是 我国第一大淡水湖泊, 同时也是长江流域最大的通江湖泊 (图 1). 鄱阳湖流域面积 $16.22 \times 10^{4} \mathrm{~km}^{2}$, 跨赣、 闽、浙、睆、湘等省份, 其中 $97 \%$ 的流域面积位于江西省境内, 约占江西省总面积的 $94 \%$. 流域属于中亚热带 湿润季风气候区, 多年平均降雨量超过 $1600 \mathrm{~mm}$, 水资源十分丰富. 据统计, 由湖口多年平均注人长江的水量 为 $1436 \times 10^{8} \mathrm{~m}^{3}$, 占长江多年平均径流量的 $16 \%$, 对长江中下游的水资源具有重要调节作用. 鄱阳湖是典型 的季节性和吞吐型湖泊, 受上游“五河” (赣江、抗河、信江、饶河和修河) 来水量和长江水位的综合作用, 湖 泊水位、容积和面积年际、年内变化较大,形成了鄱阳湖 “高水是湖、低水似河” 的特有景观. 鄱阳湖历史实测 最高水位发生在 1998 年 7 月 31 日, 湖口站的水位达到 $22.59 \mathrm{~m}$ (吴淞高程), 相应通江水体的面积和湖体容 积分别为 $3708 \mathrm{~km}^{2}$ 和 $303.63 \times 10^{8} \mathrm{~m}^{3}$; 而实测最低水位仅为 $5.9 \mathrm{~m}$ (1963 年 2 月 6 日), 相应通江水体面积为 $29 \mathrm{~km}^{2}$, 湖体容积为 $0.63 \times 10^{8} \mathrm{~m}^{3}$. 作为鄱阳湖水文情势的自然特征, 强烈的水位变化不仅形成了不同季节 湖区迥异的自然景观, 也是鄱阳湖湿地生物群落季节性演替的主要驱动力之一. 丰富的水资源和特有的水 文变化特性使得鄱阳湖湿地生态系统成为我国乃至世界上最重要和最典型的湿地生态系统之一.

鄱阳湖是全球越冬候鸟的重要栖息地,鄱阳湖国家自然保护区是我国首批列入《国际重要湿地名录》的 7 个区域之一. 目前, 全球 $98 \%$ 的濒危物种白鹤 (Grus leucogeranus)、80\% 以上的东方白鹳 (Ciconia boyciana) 和 $60 \%$ 以上的白枕鹤 (Grus vipio) 等珍稀种群在此越冬. 同时鄱阳湖还是长江江豚最重要的避难所, 鄱阳湖 栖息的江豚数量约占整个种群的 $1 / 4 \sim 1 / 3$. 此外, 鄱阳湖还兼具调蓄洪水、水源涵养、水产品供给和污染物 
降解等多项生态功能.

然而,近年来由于流域人类活动强度的不断加剧, 特别是三峡大坝的建设和流域用水量的增加, 鄱阳湖 的生态系统发生了较大的变化. 其中, 湖泊水文情势的变化被认为是鄱阳湖生态系统变化的重要驱动因素, 已经成为鄱阳湖的重要生态安全问题 ${ }^{[3]}$. 随着鄱阳湖流域经济、社会的不断发展和鄱阳湖水利枢纽工程的 运行, 鄱阳湖的水文情势特别是水位将可能发生进一步变化,湖泊生态水位研究已经成为鄱阳湖流域生态 安全和湖泊健康的重要科学问题.
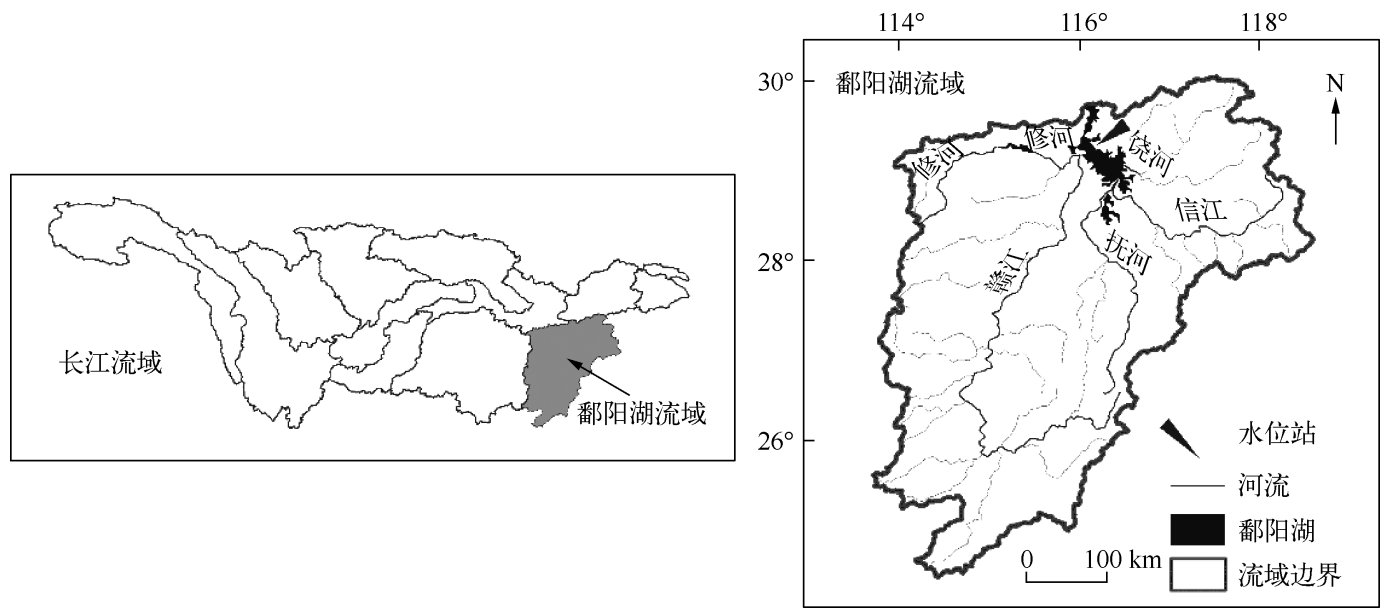

图 1 鄱阳湖流域及其水位站地理位置

Fig. 1 Location of Lake Poyang Basin and its water level gauging station

\section{2 研究方法}

1.2 .1 湖泊天然水位情势 水位情势是影响湖泊生态系统的最主要环境要素之一,湖泊的物理形态、植物和 动物的演变直接或间接受水位的控制. 水位的高低、出现时间以及变化速度等构成了水位情势的主要要素, 与湖泊生态系统的结构和功能密切相关. 评估湖泊的生态水位, 必须首先确定反映湖泊水位情势的指标, 完 整反映水位过程变化的各种属性. 相对于湖泊生态水文研究, 河流生态流量研究起步较早, 建立了较为完整 的水文变化评估指标体系, 其中代表性的方法是 IHA 法 ${ }^{[27]}$, IHA 法从流量、频率、发生时间、历时和变化速 率共 5 个方面定义了反映河流水文情势的 33 个流量指标. IHA 法对河流生态需水研究的重要意义在于认识 到河流的生态流量计算要考虑完整的水文情势变化,而不是单一地考虑最小流量. 湖泊具有与河流相似的 水文变化规律, 水位呈现年际和年内的水文变化, 对湖泊系统的多种生态结构、功能和过程有重要影响. 以 鸟类为例, 作为许多湖泊 (如鄱阳湖) 自然生态系统的顶级生物, 其数量和分布受到水位变化的影响 ${ }^{[23]}$. 研 究表明过高或过低的水位可通过影响食物和鸟类受食对鸟类生存造成不利影响 ${ }^{[23]}$; 高水位或低水位的持续 时间对浅水区和泥滩地生存的候鸟种群数量有重要影响 ${ }^{[29]}$; 高、低水位的发生时间是洲滩地植被构成和多 样性的控制因素之一, 可进一步影响鱼类生长和鸟类栖息 ${ }^{[29]}$; 而水位上升与下降过程对维持湿地的植被组 成及分布有决定性作用,被认为是维持物种多样性的重要机制之一 ${ }^{[30]}$. 因此, 从湖泊生态系统健康的要求出 发,湖泊的生态水位需要反映典型的水位情势变化. 对于一个典型水位年内呈现 “单峰” 变化的湖泊,其水位 在年内不同时期 (如汛期和非汛期)存在高低变化,形成高水位、低水位、水位上升、水位下降等变化过程. 考 虑到这些水位变化发生的时间和持续时间,那么典型的湖泊水位要素应至少包括 8 个要素: 低水位阈值、低 水位发生时间、低水位历时、高水位阈值、高水位发生时间、高水位历时、水位上升速率和水位下降速率 (图 2).

1.2 .2 水位阈值指标 湖泊生态水位的國值包括高水位國值和低水位國值, 它们分别作为界定高水位和低 水位的标准. 目前界定水位阈值的相关方法是保证率法和水位面积法 ${ }^{[7]}$. 其中, 保证率法是根据历史水文监 测资料,按照一定的频率确定水文参数. 本研究采用丰水年和枯水年常用的 $25 \%$ 和 $75 \%$ 保证率作为湖泊生 


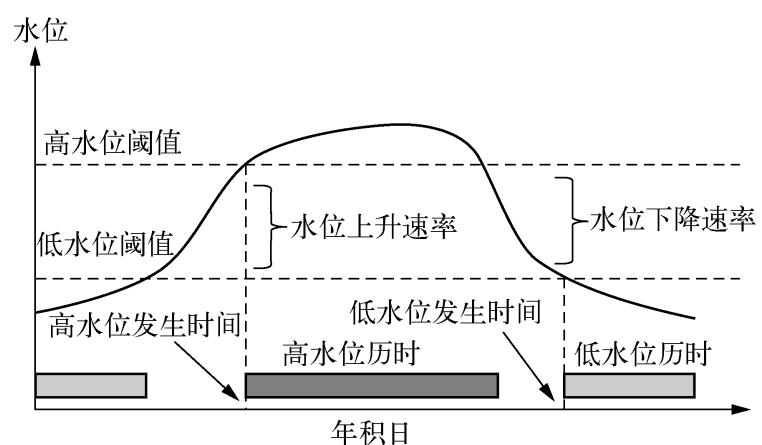

图 2 湖泊天然生态水位情势的构成

Fig. 2 Components of natural water level regimes in lakes

态水位中的高水位阈值和低水位阈值. 湖泊的 高水位阈值和低水位阈值计算公式分别为：

$$
\begin{aligned}
& H W L_{\mathrm{thr}}=\mathrm{P} 25 \%\left(W L_{i}\right) \\
& L W L_{\mathrm{thr}}=\mathrm{P} 75 \%\left(W L_{i}\right)
\end{aligned}
$$

式中, $H W L_{\mathrm{thr}}$ 和 $L W L_{\mathrm{thr}}$ 分别为高水位阈值 $(\mathrm{m})$ 和 低水位阈值 $(\mathrm{m}) ; \mathrm{P} 25 \%$ 和 $\mathrm{P} 75 \%$ 分别为 $25 \%$ 和 $75 \%$ 保证率下的湖泊日水位 $(\mathrm{m})$.

1.2 .3 发生时间指标 湖泊高水位的发生时间 是指湖泊水位初次上升至高水位阈值的日期; 低水位发生时间是指湖泊水位初次下降至低水 位阈值的日期. 湖泊高、低水位的发生时间可采 用优化模型计算. 为避免水位日波动造成的误 差, 本研究认为当连续 $7 \mathrm{~d}$ 的水位均值达到高水位國值时, 该水位才被认为属于高水位事件. 高水位发生时 间的计算模型为:

$$
H W L_{\mathrm{stim}}=\min (J D), \text { s.t. } \frac{1}{7} \sum_{i=J D}^{J D+6} D W L_{i} \geqslant H W L_{\mathrm{thr}}
$$

式中, $H W L_{\text {stim }}$ 为高水位发生时间 (年积日), $J D$ 为日期 (年积日), $D W L_{i}$ 为实测日平均水位 $(\mathrm{m})$.

与高水位发生时间类似,低水位发生时间的计算模型为:

$$
L W L_{\mathrm{stim}}=\min (J D) \text {, s.t. } \frac{1}{7} \sum_{i=J D}^{J D+6} D W L_{i} \leqslant L W L_{\mathrm{thr}}
$$

式中, $L W L_{\text {stim }}$ 为低水位发生时间 (年积日).

1.2 .4 水位历时指标 水位历时是指高、低水位事件的持续时间,可根据水位的发生日期和结束日期计算. 高水位的历时为高水位结束日期减去高水位的发生日期,具体计算公式为:

$$
\begin{gathered}
H W L_{\mathrm{dur}}=H W L_{\text {etim }}-H W L_{\text {stim }} \\
H W L_{\text {etim }}=\max (J D) \text {, s. t. } \frac{1}{7} \sum_{i=J D}^{J D+6} D W L_{i} \geqslant H W L_{\text {thr }}
\end{gathered}
$$

式中, $H W L_{\text {dur }}$ 和 $H W L_{\text {etim }}$ 分别为高水位历时 (d) 和高水位结束日期 (年积日).

同理,低水位历时的计算公式可表达为:

$$
\begin{gathered}
L W L_{\mathrm{dur}}=L W L_{\mathrm{etim}}-L W L_{\mathrm{stim}} \\
L W L_{\text {etim }}=\max (J D) \text {, s. t. } \frac{1}{7} \sum_{i=J D}^{J D+6} D W L_{i} \leqslant L W L_{\mathrm{thr}}
\end{gathered}
$$

式中, $L W L_{\text {dur }}$ 和 $L W L_{\text {etim }}$ 分别为低水位历时 (d) 和低水位结束日期 (年积日).

1.2 .5 水位变化指标 水位变化发生与高水位和低水位之间的过渡时期,包括从低水位向高水位转变时的 水位上升速率和从高水位向低水位下降时的水位下降速率,计算公式如下:

$$
\begin{aligned}
& R W L_{\mathrm{rat}}=\frac{H W L_{\mathrm{thr}}-L W L_{\mathrm{thr}}}{H W L_{\mathrm{stim}}-L W L_{\mathrm{etim}}} \\
& D W L_{\mathrm{rat}}=\frac{H W L_{\mathrm{thr}}-L W L_{\mathrm{thr}}}{L W L_{\mathrm{stim}}-H W L_{\mathrm{etim}}}
\end{aligned}
$$

式中, $R W L_{\mathrm{rat}}$ 和 $D W L_{\mathrm{rat}}$ 分别为水位上升速率 $(\mathrm{m} / \mathrm{d})$ 和水位下降速率 $(\mathrm{m} / \mathrm{d})$.

1.2.6 湖泊生态水位 在确定湖泊的高、低水位阈值后, 根据公式 (3) 至公式 (10) 可计算出其他 6 项湖泊生 
态水位的年指标值. 由于水位的年际和年内自然波动, 每年的数值存在差异, 即在天然状态下这些水位指标 并不是确定值. 因此,湖泊生态水位指标的取值也应当体现不确定性. 如果用区间表示水位指标的不确定 性,该区间具有上限和下限两个值,在这个区间内的变化都应当被认为是合理的. 借鉴 RVA 法确定河流生 态需水的标准,本研究分别取 $33 \%$ 和 $67 \%$ 分位数作为生态水位区间的上、下限.

\section{3 数据来源}

为反映湖泊水位变化的总体状况, 本研究选用的监测站点为位于鄱阳湖中部的都昌水位站 $\left(29.27^{\circ} \mathrm{N}\right.$, $116.18^{\circ} \mathrm{E}$; 图 1). 收集了该站点 $1952-2000$ 年共 49 年的日水位数据 (吴淞高程), 统计时期涵盖了鄱阳湖的 丰、平、枯水文年,同时规避了三峡大坝蓄水对湖泊水位变化造成的人为影响,能够完整体现鄱阳湖天然水 位的年内和年际变化过程. 都昌水位站的数据来源于江西省水文局.

\section{2 结果与讨论}

\section{1 鄱阳湖天然水位特征}

鄱阳湖都昌站水位年内变化为典型的单峰 分布,具有明显的高、低水位变化 (图 3). 从多年 平均值 $1952-2000$ 年) 来看, 以 7 月为界, 全年 可分为两个水位变化时期, 1 月至 7 月上旬水位 不断上升,7 月下旬至年末为水位下降阶段,呈现 出显著的高、低水位变化特征,年内日平均水位 的变化范围为 $10.4 \sim 17.9 \mathrm{~m}$. 从年际水位过程 看,多年日最大水位和日最小水位差异显著. 多 年日最大水位的变化范围为 $13.1 \sim 22.5 \mathrm{~m}$, 而多 年日最小水位的变化范围为 $8.3 \sim 14.4 \mathrm{~m}$, 同一 天的最高和最低水位之间的落差最大可达到 $10.8 \mathrm{~m}$. 根据多年日水位计算, 鄱阳湖都昌站高 水位 ( $25 \%$ 保证率) 和低水位 ( $75 \%$ 保证率) 分别 为 16.0 和 $11.7 \mathrm{~m}$, 对应的湖泊面积分别为 2640 和 $1353 \mathrm{~km}^{2}$, 相差 $1287 \mathrm{~km}^{2}$ (图 4). 总体上, 鄱阳 湖水位呈现明显的汛期高水位、非汛期低水位 的年内变化和丰、枯的年际变化特征, 并伴随着 湖泊面积的显著改变.

\section{2 高水位发生时间与历时}

基于都昌站 1952-2000 年的日水位数据, 采用公式(3)和公式 (5), 计算出鄱阳湖高水位 每年发生的日期和历时 (图 5). 从高水位发生时 间的多年变化来看,鄱阳湖高水位一般从 6 月开 始 (当年的第 $151 \mathrm{~d}$ ), 但存在较大年际波动, 变 化范围为 3-8 月 (第 $69 \sim 242 \mathrm{~d}$ ), 高水位发生 时间与年均水位呈显著的线性负相关 $\left(R^{2}=\right.$ $\left.0.34, p=8.2 \times 10^{-6}\right)$, 年均水位每升高 $1 \mathrm{~m}$, 高 水位发生时间提前约 $24 \mathrm{~d}$. 高水位历时的多年均

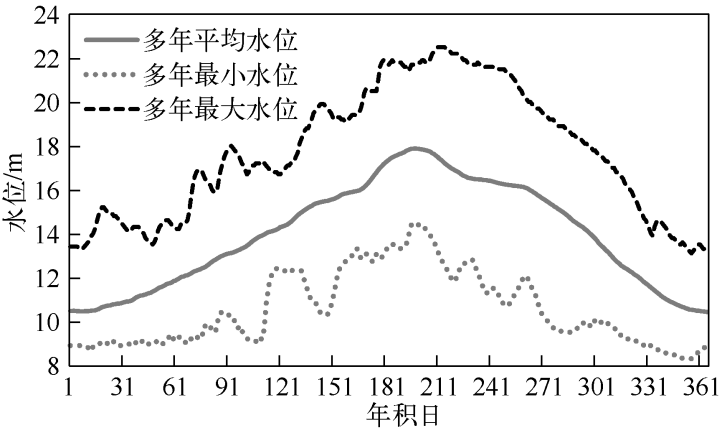

图 3 鄱阳湖都昌站 1952-2000 年日水位变化

Fig. 3 Daily water levels of Duchang Station in Lake Poyang during $1952-2000$

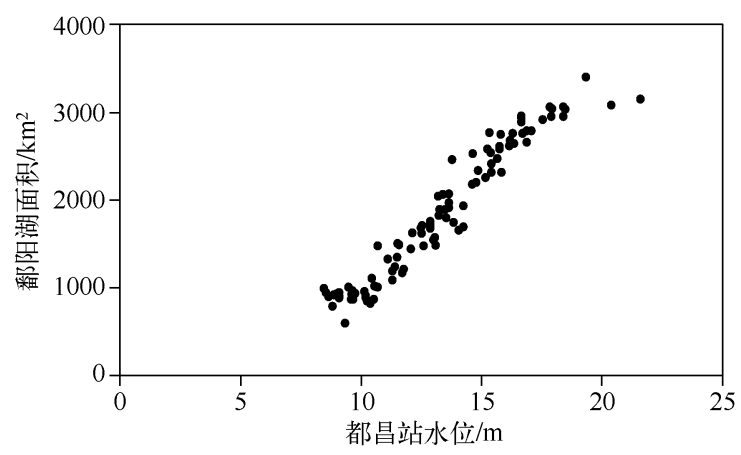

图 4 鄱阳湖都昌站水位与面积的关系 （水位和面积数据来自于文献 [28])

Fig. 4 Relationship between water level and area of Duchang Station in Lake Poyang (data is from reference[28]) 值为 $117 \mathrm{~d}$, 年际变化范围为 $13 \sim 219 \mathrm{~d}$. 高水位 历时与年均水位呈显著的线性正相关 $\left(R^{2}=0.67, p=5.4 \times 10^{-13}\right)$, 年均水位每上升 $1 \mathrm{~m}$, 高水位历时将增加 $49 \mathrm{~d}$. 以上分析表明,鄱阳湖的高水位发生时间一般在 7 月之前, 历时约 3 个月, 高水位发生的具体日期和历 时与丰、枯年份有关. 

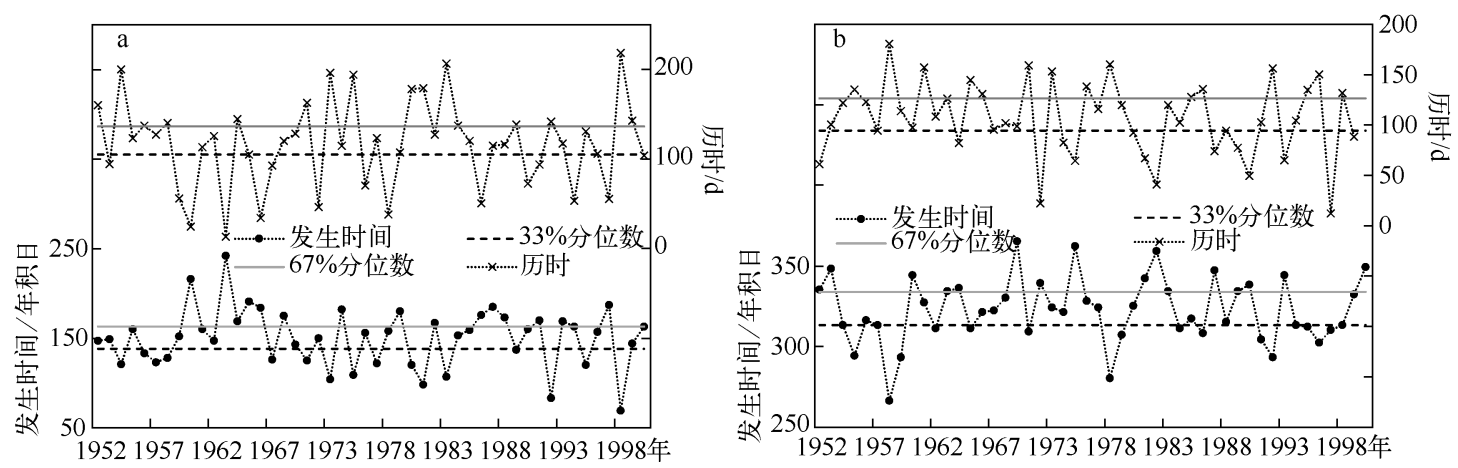

图 5 鄱阳湖都昌站 1952-2000 年高水位 (a) 和低水位 (b) 发生时间与历时

Fig. 5 Timing and duration of high water level(a) and low water level(b) of Duchang Station in Lake Poyang from 1952 to 2000

\section{3 低水位发生时间与历时}

鄱阳湖低水位一般开始于 11 月,但不同年份之间存在一定波动, 1952-2000 年记录的低水位最早和最 迟发生时间分别为 9 月和 12 月 (图 5). 相对于高水位发生时间,低水位发生时间的年际波动较小,其年际低 水位发生时间标准差 $(20 \mathrm{~d})$ 是高水位 $(33 \mathrm{~d})$ 的 $61 \%$. 从水位历时来看, 低水位的年均历时为 $107 \mathrm{~d}$, 历史上 低水位历时最大值 $(181 \mathrm{~d})$ 与最小值 $(12 \mathrm{~d})$ 相差 14 倍. 与高水位历时 $(117 \mathrm{~d})$ 相比, 低水位历时略短 (107d), 且年际变异性为 $37 \mathrm{~d}$, 低于高水位历时的标准差 (49 d). 此外, 低水位发生时间和历时与年均水位 之间没有显著的线性相关关系 $\left(R^{2}<0.1, p>0.05\right)$, 说明鄱阳湖气候条件 (丰、枯水文年) 对低水位过程的影 响较为有限, 在天然条件下, 鄱阳湖低水位的发生日期和历时相对稳定. 然而, 低水位发生日期与历时之间 存在显著的线性负相关关系 $\left(R^{2}=0.36, p=4.7 \times 10^{-6}\right)$, 即低水位发生时间越早, 其历时越短, 而发生时间 越晚,历时越长,低水位发生日期每推迟 $1 \mathrm{~d}$,低水位的历时平均延长 $1.1 \mathrm{~d}$.

\section{4 鄱阳湖水位变化率}

低水位结束和高水位开始期间是鄱阳湖水位的上升期,一般发生在 3-6 月,从多年水位值的计算结果 来看, 鄱阳湖水位上升期的平均速率为 $0.06 \mathrm{~m} / \mathrm{d}$, 变化范围在 $0.03 \sim 0.19 \mathrm{~m} / \mathrm{d}$ 之间; 水位下降期一般为 $9-$ 11 月, 其平均速率略高于上升速率, 达到 $0.10 \mathrm{~m} / \mathrm{d}$, 变化范围为 $0.04 \sim 0.23 \mathrm{~m} / \mathrm{d}$ (图 6). 水位的上升速率与 下降速率之间没有显著的线性相关关系 $(p=0.2)$, 它们与年均水位之间也无显著的线性相关关系 $(p>$ $0.4)$. 因此,与其他水位指标相比,鄱阳湖水位的变化速率具有相对独立的变化规律.

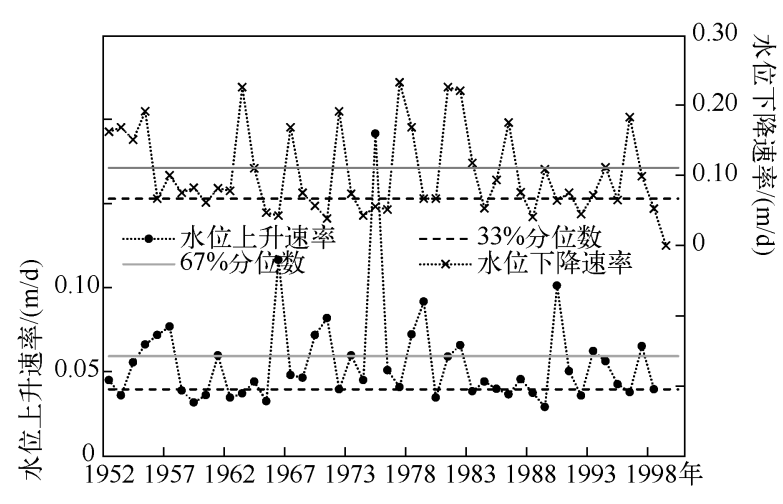

图 6 鄱阳湖都昌站 1952-2000 年水位变化速率

Fig. 6 Rising and falling rate of water level of Duchang Station in Lake Poyang from 1952 to 2000

\section{5 鄱阳湖生态水位}

依据本研究提出的生态水位计算方法,鄱 阳湖的生态水位是由高水位发生时间与历时、低 水位发生时间与历时以及水位变化速率等构成 的反映整体天然水位情势变化的指标集合. 通 过计算鄱阳湖都昌站 6 项指标多年取值, 计 算出 $33 \%$ 和 $67 \%$ 分位数数值作为生态水位的 区间阈值. 根据鄱阳湖生态水位的计算结果, 如果鄱阳湖高水位 (高于 $16.0 \mathrm{~m}$ ) 的发生时间 位于年内的第 $138 \sim 163 \mathrm{~d}$ 之间 (约为 5 月 18 日至 6 月 13 日), 历时控制在 $105 \sim 137 \mathrm{~d}$, 那 么可满足高水位所对应的生态系统功能要求 (如水生动、植物生境); 如果鄱阳湖低水位 (低于 $11.7 \mathrm{~m}$ ) 发生时间在年内的第 $313 \sim$ 
$334 \mathrm{~d}$ 之间 (约为 11 月 10 日至 12 月 1 日), 历时为 $94 \sim 126 \mathrm{~d}$, 那么与低水位相关的湖泊生态系统功能, 如候 乌越冬栖息地可得性将不会受到较大影响; 鄱阳湖的水位上升速率和下降速率分别维持在 $0.04 \sim 0.06 \mathrm{~m} / \mathrm{d}$ 和 $0.07 \sim 0.11 \mathrm{~m} / \mathrm{d}$ 时, 对水位涨落区的群落生态系统结构和功能具有重要意义.

\section{3 结论}

湖泊生态水位是维持湖泊生态系统健康的必要条件之一. 如何确定合理的湖泊生态水位是当前湖泊科 学研究的重要内容. 目前湖泊生态水位计算方法侧重于湖泊某一生态保护目标(如鱼类或鸟类)或单一水位 特征值 (如最小生态水位或最小生态水量) 的计算,忽视了水位情势的变化过程及其生态意义,所得结果难 以覆盖完整的湖泊生态系统. 基于湖泊对天然水位情势变化的适应原理,认为天然水位情势可作为湖泊生 态水位计算的重要基础. 根据水位变化过程,构建了包括高水位阈值、低水位國值、高水位发生时间、高水位 历时、低水位发生时间、低水位历时、水位上升速率和水位下降速率 8 项指标的湖泊生态水位指标体系,并 基于这些指标的多年变化特征提出了湖泊生态水位的目标值区间. 鄱阳湖的生态水位计算结果表明,维持 鄱阳湖生态系统健康所需的高水位 (高于 $16.0 \mathrm{~m}$ ) 的发生时间在年内第 $138 \sim 163 \mathrm{~d}$ 之间, 历时为 $105 \sim$ $137 \mathrm{~d}$; 低水位 (低于 $11.7 \mathrm{~m}$ ) 发生时间为年内第 $313 \sim 334 \mathrm{~d}$, 历时为 $94 \sim 126 \mathrm{~d}$; 水位上升速率和下降速率分 别应维持在 $0.04 \sim 0.06 \mathrm{~m} / \mathrm{d}$ 和 $0.07 \sim 0.11 \mathrm{~m} / \mathrm{d}$. 鉴于鄱阳湖面积巨大,水文情势在空间分布上存在一定的 差异,水位调控应考虑对不同湖区的影响. 本研究仅尝试计算了鄱阳湖都昌站点的生态水位, 反映的是全湖 平均情况,在具体的水位调控中,应进一步研究不同湖区之间的相互作用.

\section{4 参考文献}

[1 ] 马荣华,杨桂山,段洪涛等. 中国湖泊的数量、面积与空间分布. 中国科学: 地球科学,2011,41(3): 394-401.

[2] 王苏民,窦鸿身. 中国湖泊志. 北京:科学出版社,1998.

[ 3 ] 王圣瑞. 鄱阳湖生态安全. 北京:科学出版社,2014.

[ 4 ] 杨桂山,马荣华,张 路. 中国湖泊现状及面临的重大问题与保护策略. 湖泊科学,2010,22(6): 799-810. DOI 10. 18307/2010.0601

[ 5 ] Yin XA, Yang ZF. A method to assess the alteration of water-level-fluctuation patterns in lakes. Procedia Environmental Sciences, 2012, 13: 2427-2436.

[ 6 ] Yang W, Yang ZF. Effects of long-term environmental flow releases on the restoration and preservation of Baiyangdian Lake, a regulated Chinese freshwater lake. Hydrobiologia, 2014, 730(1) : 79-91.

[ 7 ] 崔保山,赵 翔,杨志峰. 基于生态水文学原理的湖泊最小生态需水量计算. 生态学报,2005,25(7):1788-1795.

[ 8 ] Wantzen KM, Rothhaupt KO, Mortl M et al. Ecological effects of water-level fluctuations in lakes: an urgent issue. Hydrobiologia, 2008, 613: $1-4$.

[ 9 ] Wilcox DA, Xie YC. Predicting wetland plant community responses to proposed water-level-regulation plans for Lake Ontario: GIS-based modeling. Journal of Great Lakes Research, 2007, 33(4) : 751-773.

[10] Hellsten S, Riihimaki J. Effects of lake water level regulation on the dynamics of littoral vegetation in northern Finland. Hydrobiologia, 1996, 340(1/2/3) : 85-92.

[11] van Geest GJ, Coops H, Roijackers RMM. Succession of aquatic vegetation driven by reduced water-level fluctuations in floodplain lakes. Journal of Applied Ecology, 2005, 42(2) : 251-260.

[12］李新虎,宋郁东,张奋东. 博斯腾湖最低生态水位计算. 湖泊科学,2007,19(2) : 177-181. DOI 10. 18307/2007.0211.

[13] 徐志侠,王 浩,唐克旺等. 吞吐型湖泊最小生态需水研究.资源科学,2005,27(3):140-144.

[14] 徐志侠,王 浩,董增川等. 南四湖湖区最小生态需水研究. 水利学报,2006,37(7):784-788.

[15] 巩琳琳,黄 强,薛小杰等. 基于生态保护目标的乌梁素海生态需水研究. 水力发电学报,2012,31(6):83-88.

[16］李新虎,宋郁东,李岳坦等. 湖泊最低生态水位计算方法研究. 干旱区地理,2007,30(4) :526-530.

[17] 梁 婕,彭也茹, 郭生练等. 基于水文变异的东洞庭湖湿地生态水位研究. 湖泊科学, 2013,25(3):330-334. DOI 10. 18307/2013.0303.

[18］梁犁丽,王 芳,汪党献等. 乌伦古湖最低生态水位及生态缺水量. 水科学进展, 2011,22(4):470-478.

[19］刘剑宇,张 强,孙 鹏等. 鄱阳湖最小生态需水研究. 中山大学学报: 自然科学版,2014,53(4):149-153. 
[20］刘正茂,吕宪国,武海涛等. 兴凯湖最低生态安全水位研究. 水利水电技术,2008,39(2):8-10,25.

[21] 罗小勇, 计 红, 邱凉. 长江流域重要湖泊最小生态水位计算及其保护对策. 水利发展研究, 2010,10(12): 36-38.

[22] Sherman DE, Kroll RW, Engle TL. Flora of a diked and an undiked southwestern Lake Erie wetland. Ohio Journal of Science, $1996,96(1): 4-8$.

[23] 陈 冰, 崔 鹏, 刘观华等. 鄱阳湖国家级自然保护区食块茎鸟类种群数量与水位的关系. 湖泊科学, 2014,26(2): 243-252. DOI 10. 18307/2014. 0211.

[24] Havens KE, Gawlik DE. Lake Okeechobee conceptual ecological model. Wetlands, 2005, 25 (4) : 908-925.

[25] Holm TE, Clausen P. Effects of water level management on autumn staging waterbird and macrophyte diversity in three Danish coastal lagoons. Biodiversity and Conservation, 2006, 15(14) : 4399-4423.

[26] Coops H, Hosper SH. Water-level management as a tool for the restoration of shallow lakes in the Netherlands. Lake and Reservoir Management, 2002, 18(4) : 293-298.

[27] Richter BD, Baumgartner JV, Wigington R et al. How much water does a river need? Freshwater Biology, 1997, 37 (1) : 231-249.

[28] 李 鹏, 封志明, 姜鲁光等. 鄱阳湖天然湖面遥感监测及其与水位关系研究. 自然资源学报, 2013, 28 (9): 1556-1568.

[29] 胡振鹏, 葛 刚, 刘成林等. 鄱阳湖湿地植物生态系统结构及湖水位对其影响研究. 长江流域资源与环境, 2010,19 (6) :597-605.

[30］姚 金金,杨桂山,万荣荣等. 水位变化对河流、湖泊湿地植被的影响. 湖泊科学, 2014,26 (6):813-821. DOI 10. $18307 / 2014.0601$. 